\title{
Can phonological awareness predict concurrent reading outcomes in a deep orthography?
}

Mila Vulchanova

Department of Language and Literature, NTNU, Norway Language Acquisition and Language Processing Lab, NTNU, Norway

mila.vulchanova@ntnu.no

Ammara Farukh

Department of Language and Literature, NTNU, Norway Language Acquisition and Language Processing Lab, NTNU, Norway English Linguistics, University of Education, Lahore, Pakistan ammara.farukh@ntnu.no

\begin{abstract}
Phonological awareness can predict reading skills in typical readers (Bradly \& Bryant, 1983; Stahl \& Murray, 1994) and can distinguish between typical reading and reading deficit in alphabetic languages (Snowling, 1981; Stanovich \& Siegel, 1994; Bryant et al., 1990). Yet the nature of phonological awareness and the causal link between phonological awareness and reading skill are subject to debate (Harm \& Seidenberg, 1999; Castles \& Coltheart, 2004; Blomert \& Willems, 2010). Phonological awareness is often defined as sensitivity to the phonological structure of language and the ability to segment, isolate and manipulate the sounds of a specific language.

We report the results of a study whose aim was to determine the sensitivity of phonological awareness tests in distinguishing between typical readers and deficit readers in Urdu. Urdu has a deep orthography, which however, presents readers with challenges different from the type offered by a language, such as English (Farukh \& Vulchanova, 2014). The tasks included in the battery were typical phonological awareness tasks, such as phoneme manipulation, rhyme oddity, rhyming, and syllabification. Our results show that none of the phonological awareness tasks successfully predict concurrent poor reading skills. Most notably, one task, syllabification, predicts reading accuracy in the Control group only, but not in the Reading Deficit group. We discuss these results in light of the grain-size hypothesis and the orthographic depth hypothesis of reading, and from the point of view of stages in literacy acquisition.
\end{abstract}

Keywords: phonological awareness, reading deficit, predictors, literacy acquisition 


\section{Resumen}

La conciencia fonológica puede predecir habilidades de lectura en los lectores típicos (Bradly \& Bryant, 1983; Stahl \& Murray, 1994) y puede distinguir entre la lectura típica y la lectua deficiente en lenguas alfabéticas (Snowling, 1981; Stanovich \& Siegel, 1994; Bryant et al., 1990). Sin embargo, se ha discutido la naturaleza de la conciencia fonológica y la conexión causal entre esta conciencia y la habilidad lectora (Harm \& Seidenberg, 1999; Castles \& Coltheart, 2004; Blomert \& Willems, 2010). La conciencia fonológica se define a menudo como la sensibilidad para con la estructura fonológica del lenguaje y la habilidad en la segmentación, aislamiento y manipulación de los sonidos de una lengua específica.

Damos cuenta de los resultados de un estudio donde pretendimos determinar la sensibilidad en los tests para distinguir entre lectores típicos y lectores con déficit en Urdu. Urdu tiene una ortografía profunda, que, sin embargo, presenta dificultades para los lectores con retos diferentes del tipo que posa por ejemplo el inglés (Farukh \& Vulchanova, 2014). Las tareas incluidas en la batería eran tareas típicas de conciencia fonológica, como manipulación de fonemas, rimas inesperadas, creación de rima, y la silabificación. Nuestros resultados muestran que ninguna de las pruebas de conciencia fonológica predice con éxito habilidades de lectura deficientes. Lo que es más, una tarea, la silabificación, predice exactitud en la lectura solamente en el grupo de Control, pero no en el grupo de lectura deficiente. Estos resultados se discuten a la luz de la hipótesis de tamaño de grano y la hipótesis de profundidad ortográfica, y desde el punto de vista de fases de la adquisición de capacidad de lectura y escritura.

Palabras clave: conciencia fonológica, deficiencia lectora, predictors, adquisición de capacidad de lectura y escritura

\section{Introduction}

Phonological awareness can predict reading skills in typical readers (Bradly \& Bryant, 1983; Stahl \& Murray, 1994) and can distinguish between typical reading and reading deficit in alphabetic languages (Snowling, 1981; Stanovich \&Siegel, 1994; Adams, 1990; Blomert \& Willems, 2010; Bryant, MacLean, Bradley, \& Crossland, 1990). Yet the nature of phonological awareness and the causal link between phonological awareness and reading skill are subject to debate (Harm \& Seidenberg, 1999; Castles \& Coltheart, 2004; Blomert \& Willems, 2010). Phonological awareness is often defined as sensitivity to the phonological structure of language and the ability to segment, isolate and manipulate the sounds of a specific language. Given that speech perception develops early in life with an early and abrupt decline in the ability to process sounds other than 
the L1 (May \& Werker, 2014), it would be natural to assume that sensitivity to the sound structure of the L1 is already in place in the years prior to reading instruction, thus supporting phonological awareness. Still, many studies observe differences in phonological awareness between trained readers and pre-literate readers (Morais, Cary, Alegria \& Bertelson, 1979; Morais, Bertelson, Cary \& Alegria, 1986). This suggests that phonological awareness is primarily a meta-linguistic skill, which depends on, and develops with, reading ability, letter knowledge and experience with orthography.

By definition phonological awareness relies on accurate phonological representations. It has been argued, for instance, that reading deficits, such as dyslexia, are caused by impaired representations. An intriguing possibility is that problems arise not as a result of impaired representations, but rather as a result of inability to access them (Ramus \& Szenkovits, 2008). Yet another alternative is that the problem resides in how visual symbols are mapped onto phonological representations dynamically when reading (Blomert and Willems, 2010).

Research in the role of phonological awareness largely depends on the nature of the tasks used to tap this construct. These tasks are directly indicative of what phonological awareness is assumed to include. Such tasks range in degree of complexity and the level of sound manipulation and analysis they target, reflecting the idea that the acoustic patterns of words can be processed and represented at different levels of granularity (Ziegler \& Goswami, 2005).

We report the results of a study whose aim was to determine the sensitivity of phonological awareness tests in distinguishing between typical readers and deficit readers in Urdu. Urdu has a deep orthography, which however, presents readers with challenges different from the type offered by a language, such as English (Farukh \& Vulchanova, 2014). The tasks included in the test battery were typical phonological awareness tasks, such as phoneme substitution, phoneme deletion, rhyme oddity, rhyming, and syllabification. The main question we asked was whether performance on these tasks can concurrently predict reading outcomes for the participants in the study and whether typical and impaired readers differed on phonological awareness. We discuss the results in light of the grain-size hypothesis and the orthographic depth hypothesis of reading, and from the point of view of stages in literacy acquisition.

\section{Phonological awareness and the nature of tasks used to study PA}

Phonological awareness can concurrently predict reading skills in typical readers (Bradly \& Bryant, 1983; Stahl \& Murray, 1994), and can also predict beginning reading ability (Bradly \& Bryant, 1983). In deep orthographies, like English, poor 
performance on phonological awareness tasks is considered to be an indicator of a phonological deficit supposed to cause reading problems, such as those found in dyslexia (e.g. Snowling, 1981; Stanovich \& Siegel, 1994; Bryant et al., 1990).

A classical problem with many theoretical constructs is the nature of the methods used to tap them. There is a variety of phonological awareness tasks (Adams, 1990; Yopp, 1988; Stahl \& Murray, 1994), that range from testing more general or holistic skills, like sensitivity to rhyme, to tasks involving individual sound manipulations e.g., phoneme-deletion, substitution, isolation etc. While, typically, phonological awareness tasks are used as a battery, without distinguishing among the individual tasks, ranking approaches suggest a gradation in terms of task-complexity and complexity of the linguistic manipulation involved. A ranking approach is consistent both with current theories in linguistics and phonology, which aim to decompose the sound structure of words at different levels of analysis, but also with approaches to dyslexia suggesting that the well-observed phonological deficit may be due to impaired processing of the underlying finer (acoustic) features of linguistic sound patterns (Goswami et al., 2011; Foxton, Talcott, Witton et al., 2003). More importantly, performance on the different tasks may reflect different stages of the development of the construct in the developing reader.

While sound-manipulation tasks are considered standard, some tasks, such as rhyming, appear more controversial. It has been suggested that, as a result of its more holistic nature, rhyming should be distinguished from other PA tasks in terms of its predictive power, and that it is different from the ability to isolate phonemes (Goswami, 1988). Still, the relationship of reading and rhyming has been validated in many studies (e.g. Bradly \& Bryant, 1985), suggesting that sensitivity to rhyme is an indicator of reading proficiency (Savage \& Frederickson, 2005; Ziegler et al., 2010), most probably modulated by the nature of the orthography (de Jong \& van der Leij, 1999).

\section{Phonological awareness and orthography}

Despite a long tradition of studying the phenomenon, the role of PA tasks in predicting reading skills is not so straightforward as assumed (Castles \& Coltheart, 2004). Results from research indicate that PA has better predictive power concerning deep orthographies. Yet, evidence both from some transparent orthographies, like Dutch (de Jong \& van der Leij, 1999), and languages with deep orthographies, such as Hebrew (Frost, 2006), suggests that more factors are involved. Different languages offer different types of challenges for the beginning reader. The most important parameter is the degree of consistency of the mapping from visual symbol (letter) to 
sound (phoneme). In some languages letters map consistently on one phoneme and for each phoneme there is a single corresponding letter (e.g., Finnish). In less consistent orthographies there may be more than one mapping in each direction (e.g., English). The mapping parameter, however, is not the only difference across orthographies.

English and Hebrew are both considered deep orthographies, yet Hebrew orthography and English orthography are deep in different ways. English is opaque for spelling-to-sound relationship, whereas depth in Hebrew orthography arises from missing phonemic (vowel) information. When diacritic marks are present in words in the text, they guide the reader for vowel sounds. In this case, Hebrew becomes a completely shallow orthography, with simple grapheme-to-phoneme conversions. However, in the absence of diacritic marks, Hebrew script gets complex, requiring recourse to syllabic and morphological structure. Similar problems have also been observed in languages that use the Arabic script (Abu-Rabia, 1997).

The orthographic depth hypothesis and the grain size theory (Frost, 2006) provide a viable account of the failure of PA tasks to predict readings skills in a language like Hebrew. The relationship of phonemes and graphemes is more direct and clear in transparent orthographies. In deep orthographies this relationship is obscured. One way of coping with this complexity is by resorting to lexical mediation (Frost, Katz, \& Bentin, 1987). Thus, when it is difficult to figure out how to pronounce a word by grapheme-phoneme correspondence, the full lexical representation of a word is recalled and the stored pronunciation is retrieved. This behaviour can be placed on a continuum defined by the dimension of orthographic depth. The extent of involvement of lexical mediation for reading a particular language depends on this dimension. In reading Hebrew, for instance, there is more lexical involvement than in English (Frost et al., 1987).

The grain size theory is a further development of the orthographic depth hypothesis (Frost et al., 1987). It adds the concept of granularity in learning to read a language (Ziegler \& Goswami, 2005). According to this theory, the development of reading is based on phonological processing and is not merely a visual task (Goswami et.al, 2001; Ziegler \& Goswami, 2005). Early vocabulary items (before literacy training starts) are stored as holistic phonological representations. When literacy training starts, the child acquires more and more words, and, as a result, a restructuring of the stored items occurs (Metsala \& Walley, 1998). In the process of restructuring, holistic lexical representations lead to syllable representations, and, finally phonemic representations are formed. A reader will only develop sensitivity to phonemes when he learns the letter-sound relationship and with exposure to orthography. Lexical restructuring is particularly relevant for deep orthographies, where letter-sound mappings are obscured. Furthermore, both literacy instruction and vocabulary growth contribute 
significantly to lexical restructuring (Ziegler \& Goswami, 2005; Dixon, Chuang \& Quiroz, 2012). Thus, phonemic awareness develops principally in response to learning about letters, and, in particular in acquiring the sound-to-letter correspondences (Morais et al., 1979; Morais et al., 1986). At the start of literacy training, phonology and orthography offer two different scales of granularity. While phonology carries a bigger grain size (phonological words), orthography offers smaller grain size (letters). As the child learns letters and graphemes, (s)he becomes aware of phonemes (smaller grains), and of the reality that letters or letter units represent phonemes. Consistency of the letter to phoneme correspondence determines how fast reading develops. The learning process assumed in re-structuring can explain findings that phonological awareness is a more sensitive predictor in deep orthographies, as they take more steps (and longer) to acquire. This is demonstrated in the results from a survey of foundation literacy in thirteen orthographies conducted by Seymour, Aro and Erskine (2003). The latter study also identifies syllabic complexity as the second crucial factor that impacts on reading outcomes across orthographies. Thus while languages like the Romance languages (Spanish, Italian) tend to have mostly open CV syllables with few initial and final consonantal clusters, and are easy for beginning readers, Germanic languages, such as Norwegian and Danish, despite being relatively transparent orthographies, present readers with challenges related to syllabic complexity (closed CVC syllables and complex consonantal clusters).

\section{Phonological awareness and reading outcomes}

The nature of phonological awareness and the causal link between phonological awareness and reading skill are subject to discussion (Harm \& Seidenberg, 1999; Ramus, Marshall, Rosen, \& van der Lely, 2013). While many studies document a strong concurrent and predictive relationship (Bradly \& Bryant, 1985; Lundeberg, Olofsson \& Wall, 1980; Perfetti, Beck, Bell \& Hughes, 1987), other studies support a reciprocal relation between phonological skills and reading performance (Goswami \& Bryant, 1990; de Jong \& van der Leij, 1999). A related issue is the extent to which reading deficits can be predicted on the basis of impaired phonological awareness, as indicated by poor performance on phonological awareness tasks. Blomert and Willems (2010) tested whether poor phonological awareness can predict reading failure in first grade in a sample of pre-literate children at familial risk for dyslexia. As many as $40 \%$ of the children in that sample went on to develop dyslexia in first grade. More surprisingly, very few among the children who developed a reading deficit in first grade were characterized by poor phonological awareness in kindergarten when they were first tested. Moreover, in kindergarten, there was no significant difference between the control and the at risk groups on any measure. Even in first grade, the main difference between the two groups was on reading fluency (which is the consequence 
of a reading deficit), and two sound-to-letter matching tasks. From all phonological awareness tasks, only phoneme deletion distinguished between the two groups at this stage. This study challenges the predictive role of phonological awareness concerning reading skills, but also the validity of phonological awareness in distinguishing between typical and impaired readers. Furthermore, Blomert \& Willems (2010) question the construct of phonological awareness itself, and whether phonological awareness actually represents a distinct and homogeneous set of oral language skills. The results from their study show that different phonological awareness tasks tap different aspects of phonological skills and different levels of processing. This study suggests that what is likely to be impaired in reading deficits is the mapping and integration of sound and visual symbol, rather than sound (phonological representations) alone. In this respect evidence from languages using non-Latin script, such as a visually complex script, e.g., Arabic, is highly relevant, yet notably under-represented.

\section{Urdu}

Similarly to Hebrew and Arabic, Urdu has a complex orthography. It has an alphabetic script borrowed from Arabic and Persian, adding some letters for the sounds which are not found in Arabic and Persian (Naim, 1999; McGregor, 1992 in Schmidt, 2003). It has thirty-eight letters and according to a recent suggestion, as many as 60 phonemes (Saleem et al., 2002). Out of the three proper vowel letters, two also represent semi-vowels. All other vowel sounds are represented by diacritics. These diacritics are placed above or below the preceding letter. When the script includes vowel diacritics, Urdu is shallow (Mumtaz \& Humphreys, 2001). However, typical Urdu writing, like Hebrew, and Arabic, omits most of the diacritics leaving only consonants behind (Rao, Vaid, Srinivasan, \& Chen, 2010). The omission of diacritics often leads to homographs and the target word can only be identified with contextual help. Thus the word kitab (book) can have the following forms $k(i) t(a) b, k(i) t(a) a b, k(i) t(o) a b$, $k(i) t(i) a b$ etc. all spelled with only consonants, leaving important morphological (and decoding) information underspecified. This is a specific challenge quite different from the problems in English orthography.

Another challenge in word decoding is the phonological structure of words and stress assignment. Urdu phonological words are multi-syllabic and display a complex phonological structure. There are many word-internal processes, such as consonant aspiration-deletion, vowel nasalization, assimilation, which, though partially predictable, complicate word segmentation. In addition, Urdu has both short and long vowels. This property affects word segmentation and stress, with a metrical structure featuring both heavy syllables (those containing long vowels) and light syllables (those with short vowels) (Hussain, 2005). 
Urdu presents the beginning reader also with visual problems related to its graphemic nature: the same letters are written in a different way in different positions within the word. Urdu also exhibits a cursive property, meaning that many graphemes in Urdu words not only look similar, but even identical, and can only be distinguished by the presence, number, or positioning of dots (Mirdehghan, 2010). Similar visual challenges have been identified for Arabic.

From the point of view of consistency, Urdu is characterised by many-to-one mappings between letter symbols and sound. These are some examples of multiple mappings both ways: $\varepsilon$, I = /a/; ت ت $/ v / ; s=/ i: /, / j /$

This means that the relation between sound and orthography is not regular and there are more than one graphemes which correspond to the same sound and more than one sound corresponding to the same grapheme (Rao et al., 2010).

In summary, Urdu presents the reader both with orthographic challenges related to the visual nature of letters, and challenges related to the absence of vowel information and the need to use context (Abu-Rabia, 1997). Furthermore, Urdu displays both syllabic complexity and greater orthographic depth seen in the multiple mapping from sound to written symbol (Seymour et al, 2003). Visual complexity and orthographic depth are also properties of the Arabic script which have been addressed in research on the acquisition of literacy in Arabic (Abu-Rabia, 1997; Ibrahim et al., 2013). A couple of studies have observed a delay in the development of phonological awareness among children learning to read Arabic (Saiegh-Haddad, 2005; Taha, 2013), most likely due to this complexity and the need for exposure to reading and writing. One of the few longitudinal studies conducted with Arabic-speaking Tunisian children, reports success only in the manipulation of syllables (Amor \& Maad, 2013).

Urdu thus offers a unique opportunity to test the extent to which phonological awareness, as measured through traditional PA tasks, predicts concurrent reading skills in deep orthographies of the Urdu type. Furthermore, one can test the extent to which such tasks can distinguish between typical and impaired readers in this type of orthography. Finally, one can check whether different skills (e.g., phonemic skills, syllabification skills, rhyming skills) can be distinguished on the basis of the tasks used.

\section{Hypotheses}

Consistent with the grain size hypothesis of reading (Ziegler \& Goswami, 2006), the complex Urdu phonological and syllabic structure and complex mapping of 
sound to orthography, coupled with the deep cursive nature of the Urdu script, we expected to observe a delay in the ability to manipulate sound at the phonemic level in readers at initial stages of reading instruction. In this respect, we expected to find sensitivity only to certain aspects of the sound patterns of words (syllabification) only in the typical readers, but not for the readers with a reading problem. Given the phonological nature of Urdu and its orthography, we also expected that the valid level of manipulation is of a bigger grain size, minimally, the level of the syllable (consonant-vowel strings).

\section{Method}

\subsection{Participants}

Participants in this study were 8-9 year-old children from 3rd grade $(\mathrm{N}=66)$ derived from a bigger sample $(\mathrm{N}=160)$ of typical and reading deficit children who participated in a prior study (Farukh \& Vulchanova, 2014). Participants attended Urdu and English medium schools in an underdeveloped district in Pakistan. In the prior study non-word repetition and a classical RAN battery were used for screening purposes in the larger sample. Scores on all rapid naming tasks, speed at reading, dictation in Urdu, and errors at repeating 4 syllable non-words were considered for further distribution of the children into more refined groups based on performance on these tasks. The children in the bigger sample who scored below the $25^{\text {th }}$ percentile on three or more tasks were classified as having a reading deficit (RD) $(N=34)$, whereas children who scored between the $25^{\text {th }}$ and $75^{\text {th }}$ percentile on three or more tasks were classified in the control group $(\mathrm{N}=32)$.

For all children in the bigger sample, reading skills (fluency and accuracy) were assessed on reading an easy short Urdu text (a total of 74 words). To ensure that the children were familiar with all words in the text, we consulted their textbooks. Because diacritics are systematically omitted in texts in school textbooks already from grade 2 on, the words in the test text were entered without diacritics.

\subsection{Materials and procedure}

Prior to the PA test, the participants were tested on selected standard nonverbal IQ tasks, which were adapted and conducted in Urdu. The IQ battery included components from WISC-IV (digit coding, picture completion, block design, arithmetic, picture assembly, picture arrangement) and some other tasks, such as Raven's matrices (Raven, Raven, \& Court, 1998) (a total of seven components). Response to IQ tasks 
is not language-, culture- and status- free (Gunderson and Siegel 2001), and thus we made sure all instructions were properly translated into Urdu to put children from both schools at an equal footing. After splitting the files on the basis of school type, independent samples t-tests for equality of means were applied (Appendix A and B) for IQ to ensure that the reading deficit group and the controls at both schools were not different on nonverbal intelligence and to rule out some other disorder. Using Bonferroni correction for 7 independent comparisons, the significance level was calculated as .0073 . The reading deficit and control groups in both types of schools did not differ significantly on any variable except for digit coding speed.

For the main part of the current study, the children from both the RD group and the Control group were tested on 8 different phonological awareness tasks. Four of the tasks tap more holistic or coarser phonological skills. These included a rhymeoddity task, asking children to identify the non-rhyming word in a set of 4 words; a rhyme pairs task asking children to detect words that paired in terms of rhyming; a syllabification task requiring children to segment words into constituent syllables, and a sound presence task asking participants to identify whether a particular sound was present in a word or not (see Appendix C). The second group of tasks tap sound manipulation, and, as such, are characterized as phonemic tasks. These included an initial phoneme substitution task, an initial phoneme deletion task, a central phoneme deletion task, and a final phoneme deletion task. Since the first set of holistic tasks target exclusively spoken language skills, they were administered orally. The second set of tasks target the smallest grain-size, and involve manipulations of individual sounds/phonemes. Since such tasks have often been shown to depend on literacy development and letter identification, they were administered through reading. Furthermore, the findings in Blomert and Willems (2010) eliminate letterknowledge as a factor distinguishing between typical and impaired readers or precursing reading achievement.

The stimuli in the PA tasks were selected from among frequent words in Urdu. For the sound manipulation tasks, it was ensured that all would result in real words after the sound manipulation. Participants were tested by the second author individually in a quiet room during school hours.

\section{Results}

In order to test our hypotheses about potential differences between the RD and the Control groups on the phonological awareness tasks, a t-test was run on all scores. The t-test is based on data from 66 children, whereas for later analyses the number was 57. Eight non-readers (children who were unable to read at all) were excluded from 
analyses where reading scores were required. There was also one missing reading score in the control group.

The results revealed no significant differences between performances of the two groups (Table.1). A trend towards significance was observed in the initial phoneme deletion task $(p=.06)$.

Table 1. T-Test explaining the mean scores differences of control group (CG) \& reading deficit group $(\mathrm{RD})$ on Phonological Awareness tasks

\begin{tabular}{lccccccc}
\hline Variables & $\begin{array}{c}\text { RDG } \\
\text { Mean } \\
\text { N=34 }\end{array}$ & $\begin{array}{c}\text { RDG } \\
(\mathrm{SD})\end{array}$ & $\begin{array}{c}\text { CG } \\
\text { Mean } \\
\mathrm{N}=32\end{array}$ & $\begin{array}{c}\text { CG } \\
\text { (SD) }\end{array}$ & T-value & df & $P$ \\
\hline InitPSub & 5.91 & 3.31 & 7.13 & 2.55 & -1.66 & 64 & .10 \\
\hline InitPDel & 5.35 & 2.49 & 6.47 & 2.13 & -1.96 & 64 & .06 \\
\hline CentPDel & 5.50 & 2.59 & 6.19 & 2.15 & -1.17 & 64 & .25 \\
\hline FinPDel & 5.29 & 2.61 & 5.78 & 2.04 & -0.84 & 64 & .40 \\
\hline SoundPres & 11.26 & 2.12 & 12.00 & 1.81 & -1.51 & 64 & .14 \\
\hline Syllab & 11.53 & 4.24 & 13.03 & 4.10 & -1.46 & 64 & .15 \\
\hline RhymOdd & 6.29 & 2.13 & 6.38 & 2.04 & -0.16 & 64 & .88 \\
\hline RhymPair & 8.32 & 1.74 & 8.88 & 1.50 & -1.38 & 64 & .17 \\
\hline
\end{tabular}

Note: Level of $p$-value significance $=.05$, Level of $p$-value significance $=.01$ (after Bonferroni correction).

$\mathrm{RDG}=$ Reading deficit group, $\mathrm{CG}=\mathrm{Control}$ group, InitPSub= Initial phoneme substitution, InitPDel $=$ Initial phoneme deletion, CentPDel $=$ Central phoneme deletion, FinPDel $=$ Final phoneme deletion, SoundPres $=$ Sound presense task, Syllab= Syllabification task, RhymOdd= Rhyme oddity task, RhymPair= Rhyming pairs.

To establish the relationship between the two reading outcomes (accuracy and fluency) and the phonological skills measures, we ran two separate multiple regression analyses using reading fluency and reading accuracy as dependent variables, and all phonological awareness tasks as independent variables, after splitting the files for group (Tables 2,3,4 \& 5). The reading fluency scores showed a skewness of 1.23 (RD group) and .93 (Control group). The skewness values for reading accuracy were -1.33 (RD group) and -2.22 (Control group). The data were then successfully normalized by using log transformation, significantly reducing the skewness values to -.12 (RD group) 
and -.11 (Control group), for fluency, and -.65 (RD group) and .28 (Control group), for accuracy, respectively.

Table 2. Summary of Multiple Regression analysis exploring predictors of reading fluency in the reading disability group

\begin{tabular}{lccccc}
\hline Variables & $\mathrm{B}$ & $\mathrm{SE}(\mathrm{B})$ & $\mathrm{Beta}$ & $\mathrm{t}$ & $\operatorname{Sig}(p)$ \\
\hline InitPSub & .03 & .06 & .32 & .49 & .63 \\
InitPDel & .05 & .07 & .47 & .80 & .44 \\
\hline CentPDel & -.05 & .05 & -.46 & -1.06 & .30 \\
\hline FinPDel & -.06 & .06 & -.64 & -.10 & .34 \\
\hline SoundPres &. .005 & .04 & .00 & .00 & .10 \\
\hline Syllab & .01 & .02 & .19 & .71 & .49 \\
\hline RhymOdd & -.05 & .05 & -.50 & -1.10 & .29 \\
\hline RhymPair & .01 & .05 & .07 & .21 & .84
\end{tabular}

Note: Level of $p$-value significance $=.05, N=57, R^{2 /} \Delta R^{2}=.09, \mathrm{~B}, \mathrm{SEB}=$ Unstandardized coefficients, Beta $=$ standardized Beta.

Table 3: Summary of Multiple Regression analysis exploring predictors of reading fluency in the control group

\begin{tabular}{lccccc}
\hline Variables & $\mathrm{B}$ & $\mathrm{SE}(\mathrm{B})$ & $\mathrm{Beta}$ & $\mathrm{t}$ & $\operatorname{Sig}(p)$ \\
\hline InitPSub & .00 & .02 & .05 & .14 & .89 \\
InitPDel & -.01 & .03 & -.13 & -.37 & .72 \\
\hline CentPDel & -.03 & .03 & -.34 & -.85 & .40 \\
\hline FinPDel & .03 & .03 & .40 & 1.20 & .24 \\
\hline SoundPres & .00 & .02 & .03 & .13 & .90 \\
\hline Syllab & -.01 & .01 & -.24 & -1.02 & .32 \\
\hline RhymOdd & .01 & .02 & -.07 & -.23 & .82 \\
\hline RhymPair & .03 & .04 & .25 & .76 & .46
\end{tabular}

Note: Level of $p$-value significance $=.05, N=57, R^{2 /} \Delta R^{2}=.09, B, S E B=$ Unstandardized coefficients, Beta $=$ standardized Beta.

As expected, no significant relationship was found between reading fluency and any of the PA tasks (Table $2 \& 3$ ). 
The regression analysis with accuracy as a dependent variable revealed a significant predictive relationship between reading accuracy and the syllabification task $(p=.02)$, while a trend towards significance was observed for the final phoneme deletion task $(\mathrm{p}=.06)$ only in the Control group, but not in the Reading Deficit group. None of the other PA tasks revealed any significant relationship with reading accuracy for any group (Table. $4 \& 5$ ).

Table 4. Summary of Multiple Regression analysis exploring predictors of reading accuracy in the reading disability group

\begin{tabular}{lccccc}
\hline Variables & $\mathrm{B}$ & $\mathrm{SE}(\mathrm{B})$ & $\mathrm{Beta}$ & $\mathrm{t}$ & $\operatorname{Sig}(p)$ \\
\hline InitPSub & -.06 & .09 & -.42 & 1.18 & .25 \\
InitPDel & -.08 & .11 & -.40 & -.62 & .55 \\
\hline CentPDel & .05 & .08 & .27 & -.66 & .52 \\
\hline FinPDel & .142 & .11 & .90 & .62 & .54 \\
\hline SoundPres & -.04 & .07 & -.17 & 1.34 & .20 \\
\hline Syllab &. .01 & .03 & -.10 & -.57 & .58 \\
\hline RhymOdd & .06 & .08 & .31 & -.36 & .72 \\
\hline RhymPair &. .02 & .08 & -.06 & .74 & .47
\end{tabular}

Level of $p$-value significance $=.05, N=57, R^{2 /} \Delta R^{2}=.09, \mathrm{~B}, \mathrm{SEB}=$ Unstandardized coefficients,

Beta $=$ standardized Beta.

1 We also considered the possibility that new analyses could be run reducing the number of predictor variables by grouping the results from the PA tasks in a meaningful way, as well as collapsing across the control group and the RD group in order to increase the sample size. We were also concerned about many of the predictor variables being at least moderately correlated. In the reported analyses all VIFs are below 10, and when we summarise the predictors, or even when we collapse over RD participants and controls to increase the sample size, the analyses did not reveal any significant predictor effects, while the VIFs are below 2 (or even 1.4 in the analysis where the two groups are collapsed). 
Table 5. Summary of Multiple Regression analysis exploring predictors of reading accuracy in the Control group

\begin{tabular}{lccccc}
\hline Variables & $\mathrm{B}$ & $\mathrm{SE}(\mathrm{B})$ & $\mathrm{Beta}$ & $\mathrm{t}$ & $\operatorname{Sig}(p)$ \\
\hline InitPSub & .05 & .04 & .37 & 1.17 & .25 \\
InitPDel & .06 & .05 & .38 & 1.29 & .21 \\
\hline CentPDel &. .04 & .05 &. .26 &. .79 & .44 \\
\hline FinPDel &. .10 & .05 &. .56 & -2.02 & .06 \\
\hline SoundPres &. .02 & .04 & -.08 & -.39 & .70 \\
\hline Syllab & .04 & .02 & .52 & 2.6 & .02 \\
\hline RhymOdd & .01 & .04 & .04 & .169 & .87 \\
\hline RhymPair &. .04 & .07 & -.19 & -.68 & .50
\end{tabular}

Level of p-value significance $=.05, N=57, R^{2 /} \Delta R^{2}=.09, \mathrm{~B}, \mathrm{SEB}=$ Unstandardized coefficients,

Beta $=$ standardized Beta.

Finally, we used a two-way multivariate analysis of variance (MANOVA) to see the effect of group (RD group and Control group). The MANOVA revealed a significant main effect of reading group $\left(F(10,46)=4.03, p=.001\right.$, Wilks' $\left.\square=.53, \mathrm{~h}_{\mathrm{p}}{ }^{2}=.47\right)$. The between-subject effects analyses revealed that the effects were significant only for reading fluency $\left(F=36.06\right.$, degrees of freedom $($ d.f. $\left.)=1, p<.001, h_{p}{ }^{2}=.40\right)$, and for reading accuracy $\left(F=17.47\right.$, d.f. $\left.=1, p<.001, \mathrm{~h}_{\mathrm{p}}{ }^{2}=.24\right)$, and not for any of the PA tasks.

\section{Discussion/Conclusion}

According to the grain size theory of reading (Ziegler \& Goswami, 2006, 2005) the recovery of phonological information depends on "reading for meaning" in any orthography. This theory suggests that reading in consistent orthographies makes use of smaller linguistic units (phonemes), but inconsistent orthographies may depend on larger units (bigger than phonemes) for decoding purposes.

The grain-size theory makes specific predictions concerning orthographies like Urdu, Hebrew and Arabic, namely that certain phonological manipulations, as required in PA tasks, may not be easy or, even possible, compared to other deep orthographies, such as English (e.g. Savage \& Frederickson, 2005; Ziegler et al., 2010). None of the PA tasks, used in the present study, except for the initial phoneme 
deletion, which showed a trend towards significance, was able to distinguish between the typical and RD groups of children. Therefore, it seems likely, that reading in Urdu, much like Hebrew or languages based on an Arabic script, depends on phonological units larger than the phoneme (e.g., consonant). Given that phonological awareness is reciprocally related to reading skills (Goswami, 1988; de Jong \& van der Leij, 1999), we can expect that the absence of vowels in Urdu script also impacts on phonological skills, requiring access to partial or complete phonological word representations from the lexicon. Urdu words are phonologically complex and comprise multiple syllables, as a result of the rich inflectional morphology of this Indo-Aryan language, suggesting that more levels of language analysis are involved in reading and require re-structuring in order to learn the mappings from visual symbol to sound. Our results point in this direction.

Among all phonological awareness tasks, only performance on initial phoneme deletion reveals a trend towards significance, and can potentially distinguish between controls and reading impaired children. A natural explanation lies in the nature of initial sounds. They are onsets in phonological structure. Typically onsets are prominent in word structure in being privileged over codas (Jakobson, 1962), easily segmentable, and frequently subject to the phonotactic constraints of a language. As such, they are natural and accessible candidates for manipulation at the early stages of phonemic awareness (Goswami, 2002).

We do not find evidence that rhyming skills in our sample predict reading performance or can distinguish between typical and impaired readers. Morais et al. (1986) suggest that there might be no relationship between reading and rhyming, as rhyming is an earlier and naturally developed phonological skill, not related to formal training or literacy like phonemic awareness (Ziegler and Goswami, 2005). Thus, rhyming can be viewed as a precursor of overall metalinguistic awareness, related to spoken language, but not directly relevant for reading. Alternatively, the lack of significance of performance on rhyming in our sample can be accounted for in terms of the complex metrical structure of Urdu (Goswami, 2002).

The split regression analyses of the two groups suggest that phonological awareness is developing faster in the control group compared to the reading deficit group. Thus, syllabification which operates with larger grain size in sound manipulation is a concurrent predictor of reading accuracy in typically developing readers (the controls), but is not yet present in the results of the reading impaired children, who are at a lower literacy level as reflected in their reading accuracy and reading fluency scores. Furthermore, we find evidence that final phoneme deletion also marginally predicts reading accuracy in controls. This result, together with the results from the initial phoneme deletion task, is largely consistent with phonological analyses of word 
structure, as well as developmental data, suggesting the prominence of word-initial (onsets) and word-final sounds (codas).

The two-way multivariate analysis of variance (MANOVA) confirmed the original distribution of the participants into two groups, the Reading Deficit group and typical readers (Controls), where we find a main effect of group on performance on both reading fluency and reading accuracy, but no effect of the PA tasks. Furthermore, the results from the bigger sample from which this one was drawn, demonstrate that non-word repetition, which is traditionally defined as a phonological processing task, is the only concurrent predictor of reading status in this larger sample (Farukh \& Vulchanova, 2014). These results provide support for the hypothesis in Blomert and Willems (2010) that rather than phonological awareness, reading skills depend on the ability to map acoustic objects to visual symbols, which is an integration or processing task. The importance of non-word repetition further suggests the intriguing possibility that children at the early stages of reading instruction in Urdu (still) depend on holistic representations, and the ability to manipulate these is what distinguishes between poor and typical readers.

Another likely, and complementary account of the results could be that the children with a reading deficit (dyslexia) have intact phonological representations, very much like their fellow typical readers (Ramus \& Szenkovits, 2008; Ramus et al., 2013). Indeed, Ramus et al. (2013) demonstrate that when a phonological test involves the least of additional cognitive effort in tapping the format of phonological representations, children with developmental dyslexia perform normally. In this case, phonological representations are tapped more directly.

We conclude from the current findings that traditional phonological awareness tasks are not a reliable concurrent predictor of reading skill in Urdu, at least not in the case of reading deficit. The present results are consistent with the grain size hypothesis (Ziegler \& Goswami 2006, 2005), and support the suggestion that in some inconsistent/deep orthographies bigger units can be more relevant for predicting reading, as confirmed by the results of the typical readers on the syllabification task. Even though this is not a longitudinal study, we have evidence of certain phonological awareness skills in the typically developing readers in our sample, but not in the reading deficit children. It thus seems that phonological awareness takes more time to develop in deep orthographies using the Arabic script, as a result of the complex visual and phonological structure of words in such languages (Saiegh-Haddad, 2005, 2007; Taha, 2013). We can thus recommend that screening batteries for Urdu should include units of a bigger size (rather than just phonemes), in order to reliably differentiate between typical readers and children with a reading deficit. More research is needed to establish the exact level of granularity that such tasks should tap, and the extent to 
which morphological structure is involved. Also, data from typical and impaired adult readers are necessary, as well as from increased sample sizes for children.

\section{References}

Adams, M. R. (1990). The demands and capacities model I: Theoretical elaborations. Journal of Fluency Disorders, 15(3), 135-141. doi: http://dx.doi. org/10.1016/0094-730X(90)90014-J

Abu-Rabia, S. (1997). Reading in Arabic orthography: The effect of vowels and context on reading accuracy of poor and skilled native Arabic readers. Reading and Writing: An Interdisciplinary Journal 9, 65-78.

Amor, M. \& Ridha Ben Maad, M. (2013). The role of Arabic orthographis lietracy in the phonological awareness of Tunisian children. International Journal on New trends in Education and their Implications, 4(2), 15-23.

Blomert, L., \& Willems, G. (2010). Is there a causal link from a phonological awareness deficit to reading failure in children at familial risk for dyslexia? DYSLEXIA, 16(4), 300-317. doi: $10.1002 /$ dys.405

Bradley, L., \& Bryant, P. E. (1983). Categorizing sounds and learning to read[mdash]a causal connection. [10.1038/301419a0]. Nature, 301(5899), 419-421.

Bradley, L., \& Bryant, P. (1985). Rhyme and reason in reading and spelling (No. 1). Ann Arbor: University of Michigan Press.

Bryant, P. E., MacLean, M., Bradley, L. L., \& Crossland, J. (1990). Rhyme and alliteration, phoneme detection, and learning to read. Developmental Psychology, 26(3), 429-438. doi: 10.1037/0012-1649.26.3.429

de Jong, P. F., \& van der Leij, A. (1999). Specific contributions of phonological abilities to early reading acquisition: Results from a Dutch latent variable longitudinal study. Journal of Educational Psychology, 91(3), 450-476. doi: 10.1037/0022-0663.91.3.450

de Jong, P. F., \& van der Leij, A. (2003). Developmental changes in the manifestation of a phonological deficit in dyslexic children learning to read a regular orthography. Journal of Educational Psychology, 95(1), 22-40. doi: 10.1037/0022-0663.95.1.22

Deutsch, A., Frost, R., \& Forster, K. I. (1998). Verbs and nouns are organized and accessed differently in the mental lexicon: Evidence from Hebrew. Journal of Experimental Psychology: Learning, Memory, and Cognition, 24(5), 1238-1255. doi: 10.1037/0278-7393.24.5.1238

Dixon, L. Q., Chuang, H.-K., \& Quiroz, B. (2012). English phonological awareness in bilinguals: a cross-linguistic study of Tamil, Malay and Chinese English- 
language learners. Journal of Research in Reading, 35(4), 372-392. doi: 10.1111/j.14679817.2010.01471.x

Farukh, A., \& Vulchanova, M. (2014). Predictors of Reading in Urdu: Does deep orthography have an impact? Dyslexia, 20 (2), 146-166.

Foxton, J. M., Talcott, J. B., Witton, C., Brace, H., McIntyre, F., \& Griffiths, T. D. (2003). Reading skills are related to global, but not local, acoustic pattern perception. Nature neuroscience, 6(4), 343-344.

Frost, R. (1994). Prelexical and postlexical strategies in reading: Evidence from a deep and a shallow orthography. Journal of Experimental Psychology: Learning, Memory, and Cognition, 20(1), 116-129. doi: 10.1037/0278-7393.20.1.116

Frost, R. (2006). Becoming literate in Hebrew: the grain size hypothesis and Semitic orthographic systems. Developmental science, 9(5), 439.

Frost, R., Forster, K. I., \& Deutsch, A. (1997). What can we learn from the morphology of Hebrew: A masked priming investigation of morphological representation. Journal of Experimental Psychology: Learning, Memory, \& Cognition, 23, 829-856.

Frost, R., Katz, L., \& Bentin, S. (1987). Strategies for visual word recognition and orthographical depth: A multilingual comparison. Journal of Experimental Psychology: Human Perception and Performance, 13(1), 104-115. doi: 10.1037/0096-1523.13.1.104

Goswami, U. (1988). Orthographic analogies and reading development. The Quarterly Journal of Experimental Psychology Section A, 40(2), 239-268. doi: 10.1080/02724988843000113

Goswami, U., \& Bryant, P. (1990). Phonological skills and learning to read. Hove: Erlbaum.

Goswami U, Wang H-L, Cruz A, Fosker T, Mead N \& Huss M (2011). Languageuniversal sensory deficits in developmenta dyslexia: English, Spanish and Chinese. Journal of Cognitive Neuroscience, 23, 325-337.

Harm, M. W., \& Seidenberg, M. S. (1999). Phonology, reading acquisition, and dyslexia: Insights from connectionist models. Psychological Review, 106(3), 491-528. doi: 10.1037/0033-295x.106.3.491

Hussain, S. (2005). Phonological processing for Urdu Text to Speech system. Contemporary Issues in Nepalese Linguistics (eds. Yadava, Bhattarai, Lohani, Prasain and Parajuli), Linguistics Society of Nepal.

Ibrahim, R. , Khateb, A. \& Taha, H. (2013). How Does Type of Orthography Affect Reading in Arabic and Hebrew as First and Second Languages?. Open Journal of Modern Linguistics, 3, 40-46. doi: 10.4236/ojml.2013.31005. 
Jakobson, R. (1962) Selected writings I: Phonological studies. The Hague: Mouton.

Lundberg, I., Olofsson, Å., \& Wall, S. (1980). Reading and spelling skills in the first school years predicted from phonemic awareness skills in kindergarten. Scandinavian Journal of Psychology, 21(1), 159-173. doi: 10.1111/j.1467-9450.1980.tb00356.x

May, L., \& Werker, J.F. (2014). Can a Click be a Word?: Infants' Learning of NonNative Words. Infancy, 19(3), 281-300.

McGregor, R. S. (1992). Urdu Study Materials for use with Outline of Hindi Grammar. New Delhi: Oxford University Press.

Metsala, J.L., \& Walley, A.C. (1998). Spoken vocabulary growth and the segmental restructuring of lexical representations: Precursors to phonemic awareness and early reading ability. In J.L. Metsala \& L.C. Ehri (Eds.), Word recognition in beginning literacy (pp. 89-120). Mahwah, NJ: Lawrence Erlbaum Associates.

Mirdehghan, M. (2010). Persian, Urdu, and Pashto: A comparative orthographic analysis. Writing Systems Research, 2(1):9-23.

Morais, J., Bertelson, P., Cary, L., \& Alegria, J. (1986). Literacy training and speech segmentation. Cognition, 24(1-2), 45-64. doi: http://dx.doi.org/10.1016/00100277(86)90004-1

Morais, J.,Cary, L., Alegria, J., \& Bertelson, P. (1979). Does awareness of speech as a sequence of phones arise spontaneously? Cognition, 7(4), 323-331. doi: http://dx.doi. org/10.1016/0010-0277(79)90020-9

Mumtaz, S., \& Humphreys, G. (2001). The effects of bilingualism on learning to read English: evidence from the contrast between Urdu-English bilingual and English monolingual children. Journal of Research in Reading, 24(2), 113-134.

Naim, C. M. (1999). Introductory Urdu. Chicago: University of Chicago, Committee on Southern Asia Studies.

Perfetti, C. A., Beck, I., Bell, L. C., \& Hughes, C. (1987). Phonemic knowledge and learning to read are reciprocal: A longitudinal study of first grade children. MerrillPalmer Quarterly, 283-319.

Ramus, F., Marshall, C. R., Rosen, S., \& van der Lely, H. K. J. (2013). Phonological deficits in specific language impairment and developmental dyslexia: towards a multidimensional model. Brain, 136(2), 630-645. doi: 10.1093/brain/aws356

Ramus, F., \& Szenkovits, G. (2008). What phonological deficit? The Quarterly Journal of Experimental Psychology, 61(1), 129-141. doi: 10.1080/17470210701508822

Rao, C., Vaid, J., Srinivasan, N., \& Chen, H.-C. (2010). Orthographic characteristics speed Hindi word naming but slow Urdu naming: evidence from 
Hindi/Urdu biliterates. Reading and Writing, 24(6),679-695. doi: 10.1007/s11145010-9256-9

Saiegh-Haddad, E. (2005). Correlates of reading fluency in Arabic: Diglossic and orthographic factors. Reading and Writing, 18, 559-582.

Saiegh-Haddad, E. (2007). Linguistic constraints on children's ability to isolate phonemes in Arabic. Applied Psycholinguistics, 28, 607-625.

Saleem, A., Kabir, H., Riaz, M., Rafique, M., Khalid, N. and Shahid, S. (2002). Urdu Consonantal and Vocalic Sounds. CRULP Annual Student Report, Akhbar-eUrdu, National Language Authority, Islamabad, Pakistan.

Savage, R., \& Frederickson, N. (2005). Evidence of a highly specific relationship between rapid automatic naming of digits and text-reading speed. Brain and Language, 93(2), 152-159. doi: 10.1016/j.bandl.2004.09.005

Schmidt, R. L. (2003). Urdu. In G. Cardona \& D. Jain (Eds.), The Indo-Aryan Languages (pp. 286-350). London: Routledge, Taylor \& Francis Group.

Seymour, P.H., Aro, M. \& Erskine, J.M. (2003). Foundation literacy acquisition in European orthographies. British Journal of Psychology, 94, 143-174.

Snowling, M. (1981). Phonemic deficits in developmental dyslexia. Psychological Research, 43(2), 219-234. doi: 10.1007/bf00309831

Stahl, S. A., \& Murray, B. A. (1994). Defining phonological awareness and its relationship to early reading. Journal of Educational Psychology, 86(2), 221-234. doi: 10.1037/0022-0663.86.2.221

Stanovich, K. E., \& Siegel, L. S. (1994). Phenotypic performance profile of children with reading disabilities: A regression-based test of the phonological-core variabledifference model. Journal of Educational Psychology, 86(1), 24-53. doi: 10.1037/00220663.86.1.24

Taha, H. Y. (2013). Reading and spelling in Arabic: Linguistic and orthographic complexity. Theory and Practice in Language Studies, 3 (5), 721-727.

Wimmer, H. (1996). The Nonword Reading Deficit in Developmental Dyslexia: Evidence from Children Learning to Read German. Journal of Experimental Child Psychology, 61(1), 80-90. doi: http://dx.doi.org/10.1006/jecp.1996.0004

Yopp, H. K. (1988). The validity and reliability of phonemic awareness tests. Reading Research Quarterly, 159-177.(Farukh \& Vulchanova, 2014; Frost, 2006; Johannes C. Ziegler \& Goswami, 2006)

Ziegler, J. C., Bertrand, D., Tóth, D., Csépe, V., Reis, A., Faísca, L., Blomert, L. (2010). Orthographic depth and its impact on universal predictors of 
reading: a cross-language investigation. Psychological Science, 21(4), 551-559. doi: $10.1177 / 0956797610363406$

Ziegler, J. C., \& Goswami, U. (2005). Reading Acquisition, Developmental Dyslexia, and Skilled Reading Across Languages: A Psycholinguistic Grain Size Theory. Psychological bulletin, 31(1), 3-29. doi: 10.1037/0033-2909.131.1.3

m.m. (2006). Becoming literate in different languages: similar problems, different solutions. Developmental science, 9(5), 429-436. doi: 10.1111/j.1467-7687.2006.00509.x 

